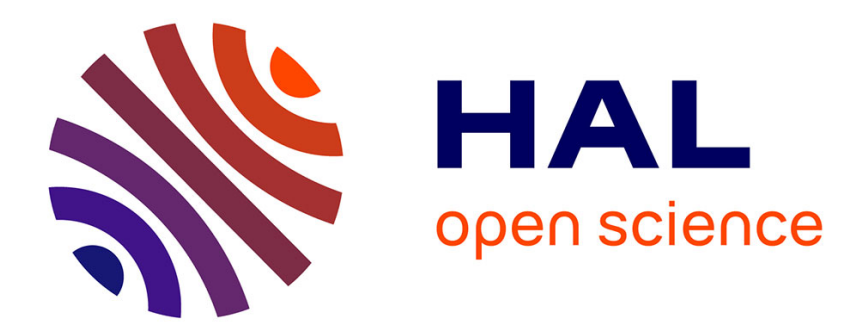

\title{
Crystal growth by solvent techniques and characteristic properties of CdTe
}

\author{
T. Taguchi, J. Shirafuji, Y. Inuishi
}

\section{To cite this version:}

T. Taguchi, J. Shirafuji, Y. Inuishi. Crystal growth by solvent techniques and characteristic properties of CdTe. Revue de Physique Appliquée, 1977, 12 (2), pp.117-122. 10.1051/rphysap:01977001202011700 . jpa-00244129

\section{HAL Id: jpa-00244129 https://hal.science/jpa-00244129}

Submitted on 1 Jan 1977

HAL is a multi-disciplinary open access archive for the deposit and dissemination of scientific research documents, whether they are published or not. The documents may come from teaching and research institutions in France or abroad, or from public or private research centers.
L'archive ouverte pluridisciplinaire HAL, est destinée au dépôt et à la diffusion de documents scientifiques de niveau recherche, publiés ou non, émanant des établissements d'enseignement et de recherche français ou étrangers, des laboratoires publics ou privés. 


\title{
CRYSTAL GROWTH BY SOLVENT TECHNIQUES AND CHARACTERISTIC PROPERTIES OF CdTe
}

\author{
T. TAGUCHI, J. SHIRAFUJI and Y. INUISHI
}

Faculty of Engineering Osaka University Suita, Osaka, 565, Japan

\begin{abstract}
Résumé. - On a déterminé les conditions optimales de croissance de monocristaux de tellurure de cadmium non dopés à partir d'une solution riche en tellure par la méthode THM. Dans nos conditions expérimentales, il apparaît qu'une température de croissance de $650^{\circ} \mathrm{C}$ et une vitesse de $3 \mathrm{~mm}$ par jour constituent le meilleur choix. Dans ces conditions, les cristaux de type p présentent une résistivité de $10^{6} \Omega . \mathrm{cm}$. Lorsqu'une suppression de cadmium règne au-dessus de la solution de tirage, la résistivité peut même atteindre $8 \times 10^{6} \Omega . \mathrm{cm}$. Pour une pression de cadmium convenable des cristaux de bonne qualité peuvent être obtenus dans lesquels les porteurs ont des longueurs de diffusion importantes. D'autres études de caractérisation de ces matériaux sont présentées utilisant les propriétés de transport des porteurs ou des mesures de photoluminescence.
\end{abstract}

\begin{abstract}
Optimum growth conditions to grow pure single crystals from Te-rich solution by the Traveling Heater Method are investigated. For the growing apparatus employed, the optimum conditions are determined to be a growth temperature of $650^{\circ} \mathrm{C}$ and a growth rate of $3 \mathrm{~mm} /$ day. The room temperature resistivity which we obtain in undoped p-type crystals extends to nearly $10^{6} \Omega . \mathrm{cm}$. When the Cd pressure over the Te solution is controlled during crystal growth, the room temperature resistivity can be increased to $8 \times 10^{6} \Omega . \mathrm{cm}$. Characterization of the crystals grown by the Traveling Heater Method is also carried out by means of carrier transport and photoluminescence measurements, and it can be shown that under an appropriate $\mathrm{Cd}$ pressure, excellent crystals with good transport properties for both electrons and holes are obtained.
\end{abstract}

1. Introduction. - CdTe is a very promising material for the fabrication of $\gamma$-ray spectrometers operating at room temperature because of its large mean atomic number coupled with a sufficiently high bandgap and reasonable mobilities for both carriers. Thus, the past five years have seen much work devoted to explore its properties for this purpose including crystal growth, radiation detector fabrication and electrical characterization [1-7]. However, to date lack of very high energy resolution is still a drawback in these devices and the lack of performance has generally been attributed to carrier trapping [8-10] Martin et al. [9] have suggested two levels which limit $\tau_{\mathrm{h}}^{+}$ but they also showed that for the better values of $\tau_{\mathbf{h}}^{+}$, which ranged up to $1500 \mathrm{~ns}$, excellent detector performance can be achieved.

Shallow electron trapping levels at 0.02 and $0.05 \mathrm{eV}$ have also been found $[5,10]$ but they influence detector performance at room temperature only a little, but a deeper trapping level at $\mathrm{E}_{\mathrm{C}}-0.6 \mathrm{eV}$ can reduce $\mu \tau_{e}^{+},[10]$ and more seriously, levels of such depth have been implicated in causing detector polarization $[5,11]$. This latter level is somewhat speculatively assigned to be a doubly ionized cadmium vacancy $\left(V_{\mathrm{Cd}}^{\prime \prime}\right)$. Such vacancies are inevitably created during donor doping since CdTe has a strong tendency for self compensation

However, in spite of a great deal of investigation, the detailed origin of all the traps is still unclear, even though there is general agreement that most of them are due to either native defects, in particular $\mathrm{Cd}$ vacancies, or their association with various donor dopants.

But even in undoped material grown from Te solution at low temperature there is still a small deviations from stoichiometry, causing $\mathrm{Cd}$ vacancies. If such vacancies then are held responsible in one way or the other, for causing trapping or polarization, any possible reduction in the vacancy content is of course extremely important. The present paper then concerns itself with the question as to whether the vacancy content could be reduced by introducing a $\mathrm{Cd}$ overpressure during crystal growth from Te solutions.

2. Crystal growth from Te-rich solution. - Although a variety of methods have been used to grown CdTe for $\gamma$-ray detector purposes, we have convinced ourselves that growth from Te-rich solutions, in particular using the Traveling Heater Method (THM)[1] is the simplest and most reliable way to obtain the material for the purpose. This is due to the following advantages :

i) reduced contamination from the crucible ;

ii) low growth temperatures, which decreases the native defect content;

iii) the gettering effects of the solvent metal. 


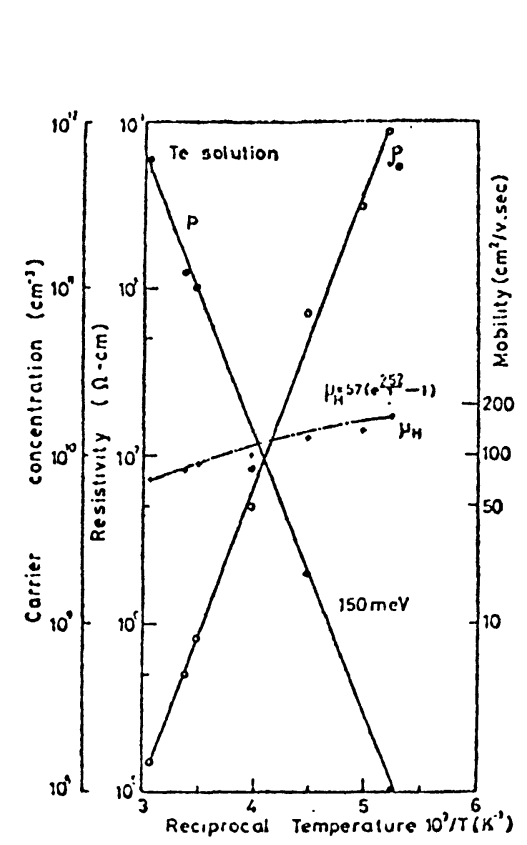

(a)

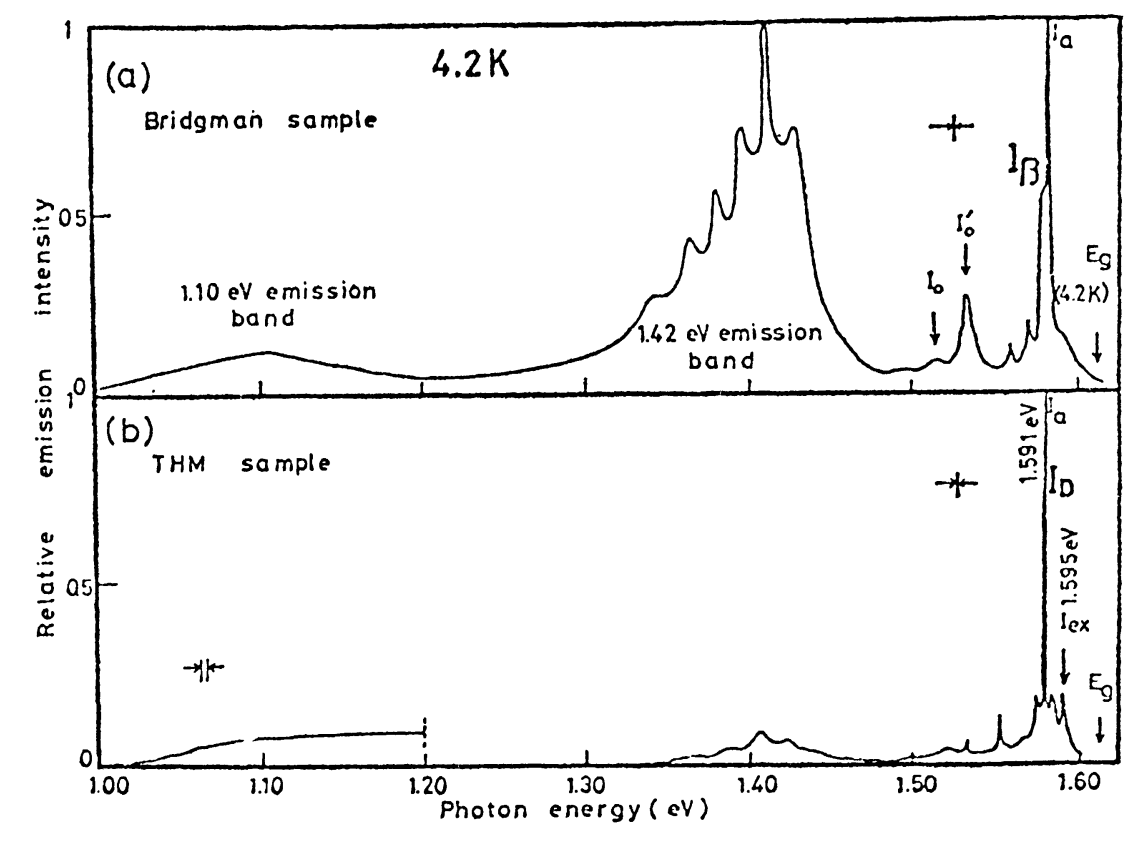

(b)

FIG. 1. - a) Electrical properties of THM grown crystals demonstrating p-type behavior dominated by $\mathrm{E}_{\mathrm{v}}+0.15 \mathrm{e}$ Vacceptors. b) Comparison of photoluminescence spectra of Bridgman and THM grown CdTe.

It should be mentioned here that vapor growth, aside from not providing gettering effects, should show similar advantages though, but it has not been widely used yet for the growth of large crystal volumes of CdTe.

We have confirmed the higher purity of Te grown crystals which has been reported before [1, 15] using ion beam microanalysis. Compared with Bridgman crystals, $\mathrm{Fe}, \mathrm{Al}, \mathrm{Si}, \mathrm{Cr}$ and $\mathrm{Ca}$, which are the dominant impurities, are all considerably reduced. Furthermore, figure 1 demonstrates the remarkable reduction in the $1.42 \mathrm{eV}$ emission in a photoluminescence spectrum taken at $4.2 \mathrm{~K}$, when Bridgmen grown and solution grown material are compared.

However, we have observed that the characteristics of the Te grown material are very dependent on the growth conditions such as growth rate and temperature. Figure 2 shows a schematic representation of our growth setup [13]. The width of the Te zone at the center of the furnace is chosen to be $10 \mathrm{~mm}$. Material grown by the Bridgman method is used as feed in a quartz tube with an inner diameter of typically 10$15 \mathrm{~mm}$. The growth temperature at the central zone (zone 3) and the growth rate are separately varied to obtain optimum growth conditions. Figure 3 shows the relation between the growth temperature and the room temperature electrical properties for undoped material grown at $3 \mathrm{~mm} /$ day and $5 \mathrm{~mm} /$ day. Both of these rates give essentially the same results. We see that the hole mobility is virtually constant at about $90 \mathrm{~cm}^{2} / \mathrm{V}$ s for all temperatures studies, but the hole concentration which could be confirmed to be gover-

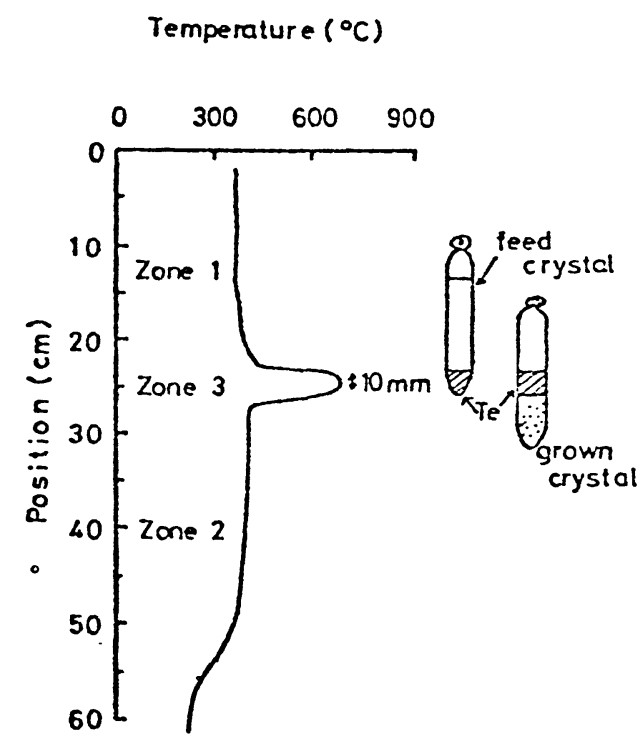

Fig. 2. - Schematic representation of CdTe crystal growth from Te-solution by THM.

ned by acceptors at $\mathrm{E}_{\mathrm{V}}+0.15 \mathrm{eV}$, increases rather rapidly at growth temperatures over $675^{\circ} \mathrm{C}$. A semilogarithmic plot of hole concentration vs. $1 / \mathrm{T}$ yields an activation energy of about $3.0 \mathrm{eV}$, a rather high value which is not readily understood.

The dependence of the electrical properties on the growth rate over a larger range of rates at $675^{\circ} \mathrm{C}$ is shown in figure 4 . From about $7 \mathrm{~mm}$ /day upwards, the results get progressively worse in electrical terms, 


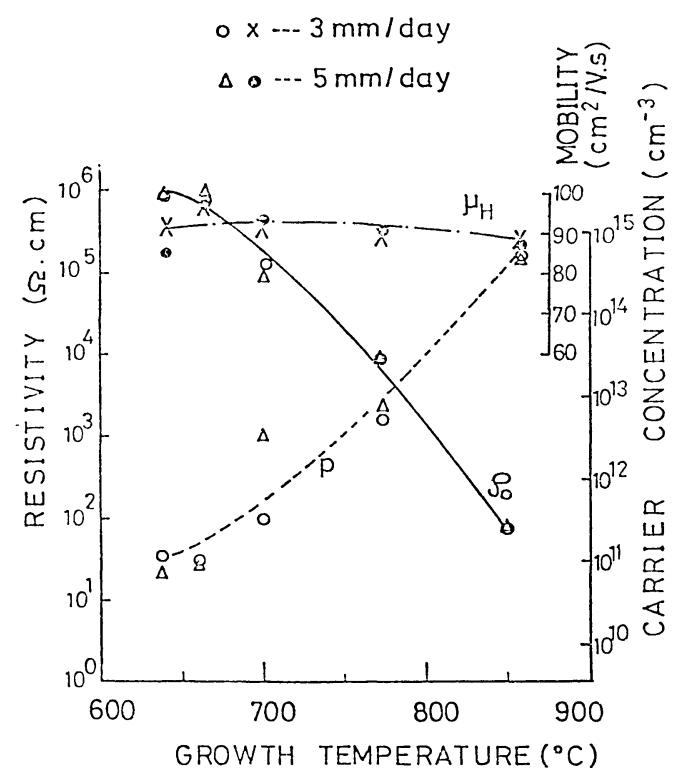

FIG. 3. - Effect of growth temperature on the room temperature electrical properties of THM grown material at two constant rates $(3 \mathrm{~mm} /$ day and $5 \mathrm{~mm} /$ day $)$.

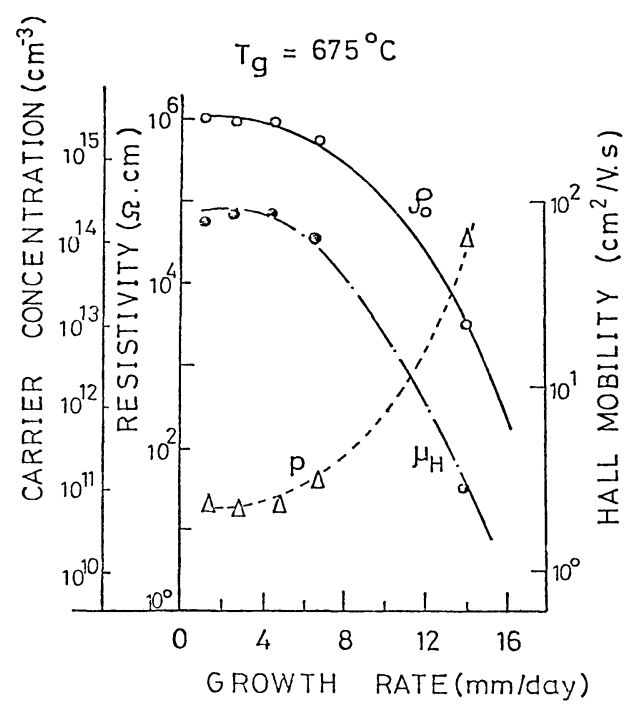

Fig. 4. - Effect of growth rate on the room temperature electrical propertes of HM grown CdTe at a constant growth temperature of $675^{\circ} \mathrm{C}$

and on exceeding $14 \mathrm{~mm} /$ day, we can only obtain polycrystalline ingots. This is a clear improvement in the growth rate for single crystal ingots over the results reported by Bell et al. [1].

From these results, we reach the conclusion that for our particular furnace the conditions for growing crystals with optimum electrical transport properties a rate of $3 \mathrm{~mm} /$ day at $650^{\circ} \mathrm{C}$, although some tolerance on these values is probably allowed. Under these conditions we obtain resistivities as high as $10^{6} \Omega . \mathrm{cm}$ for our not intentionally doped crystals.
Also, studies of etch pit densities reveal very low values of $5 \times 10^{2} / \mathrm{cm}^{2}$ for these conditions and a gradual increase to about $10^{3} / \mathrm{cm}^{2}$ as the growth temperature is increased. However, when the rate is increased over $3 \mathrm{~mm} /$ day, dramatic increases in etch pit density are observed. No improvements in any of the properties are noted, however, when the rate is decreased below $3 \mathrm{~mm} /$ day.

3. Effect of Cd overpressure on THM crystals. Although fairly pure crystals can be grown by THM, the p-type conductivity of the resulting CdTe is still governed by the $\mathrm{E}_{\mathrm{V}}+0.15 \mathrm{eV}$ acceptors which are caused by a complex containing Cd-vacancies. Thus, one is led to the idea that kinetic limitations of Cdtransport of CdTe interface dissolution in non-steady state conditions and lead to excess $\mathrm{Cd}$ vacancy introduction, which might explain the various dependencies of the electrical properties on temperature and growth rate which have been described above. Consequently, if one could control the Cd-overpressure over the Te solution, one might be able to reduce the $\mathrm{Cd}$ vacancy concentration.

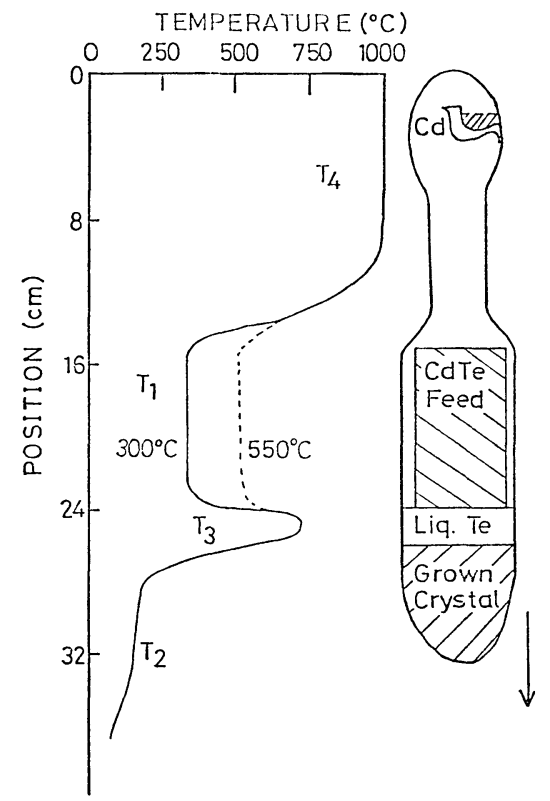

Fig. 5. - Schematic of THM growth of CdTe under controlled Cd-overpressures.

Hence, we modified the THM method to obtain a controlled $\mathrm{Cd}$ overpressure as shown in figure 5, which should be studied carefully. As can be seen, we control the temperature of a Cd reservoir between $1000^{\circ} \mathrm{C}$ and $1140^{\circ} \mathrm{C}$ but we believe the $\mathrm{Cd}$ pressure in the upper part of the ampoule to be effectively controlled by $T_{1}$, the temperature of the feed region. Temperatures between $300^{\circ} \mathrm{C}$ and $560^{\circ} \mathrm{C}$ are used for $T_{1}$ and the growth temperature is held constant at $700{ }^{\circ} \mathrm{C}$ with a rate of $3 \mathrm{~mm} /$ day. 
The electrical results obtained are plotted in figure 6 . Increasing $T_{1}$, the resistivity increases until it reaches a maximum of $8 \times 10^{6} \Omega . \mathrm{cm}$ for $T_{1}=480^{\circ} \mathrm{C}$. When $T_{1}$ is raised over $500^{\circ} \mathrm{C}$ the room temperature resistivity decreases as $P_{\mathrm{Cd}}^{-1 / 3}$ if we assume the $\mathrm{Cd}$ pressure to be indeed determined by the temperature $T_{1}$ of the CdTe feed, but p-type conductivity is maintained.

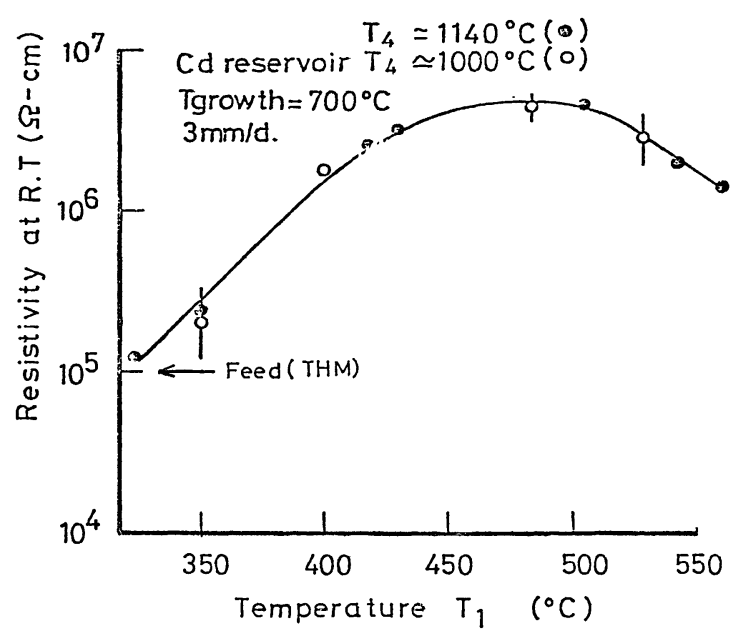

FIG. 6. - Resistivity as a function of feed temperature with two constant $\mathrm{Cd}$ reservoir temperatures.

To look at the most extreme condition, we also obtained crystals grown from pure Cd solution in steady state. Such crystals now show n-type conductivity governed by donors at about $\mathrm{E}_{\mathrm{C}}-0.05 \mathrm{eV}$. Figure 7 shows photoluminescence spectra at $4.2 \mathrm{~K}$ and $77 \mathrm{~K}$ for crystals grown under various $\mathrm{Cd}$ overpressures, where the Cd overpressure again is deduced simply from $T_{1}$. The emission intensity of the $1.42 \mathrm{eV}$ band, however, increases monotomically even beyond the point where the resistivity starts to decrease.

4. Detailed photoluminescence results. - Photoluminescence measurements allow information to be obtained concerning localized levels due to impurities and defects [14].

So ar as the $1.42 \mathrm{eV}$ band is concerned (Fig. 1) we can show, that, qualitatively at least, it increases when donor doping increases, which is the case for introduction of $\mathrm{Cl}, \mathrm{Br}, \mathrm{In}, \mathrm{Ga}, \mathrm{Li}$, and $\mathrm{Cd}$ interstitials. This we ascribe to the fact that all these donors cause increases in the Cd-vacancy concentration due to self compensation effects. And we feel it is confirmed also by the facts presented in figure 7, which show that with increasing Cd-overpressures the $1.42 \mathrm{eV}$ emission intensity increases, even though at the higher pressures the resistivity decreases. This decrease then is ascribed to $\mathrm{Cd}$ interstitial formation due to the fact that the resistance has a $P_{\mathrm{Cd}}^{-1 / 3}$ dependence on $\mathrm{Cd}$ overpressure [15]. Finally, however, when crystals are grown from Cd-solution, we find an emission line
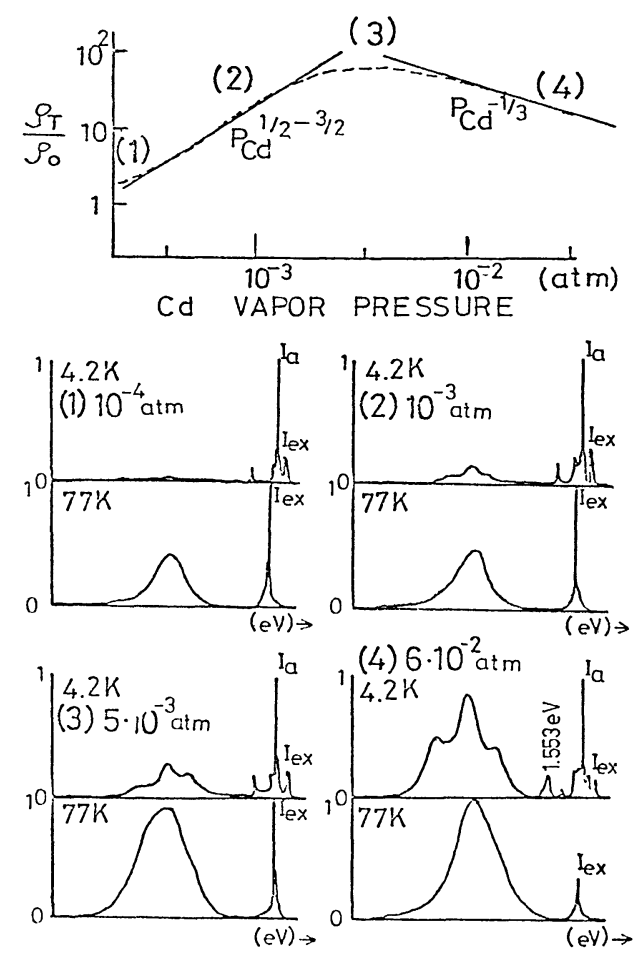

FIG. 7. - a) Ratio of the resistivity at a specific Cd overpressure (assumed to depend only on the feed temperature $T_{1}$ ) to the restivity of CdTe grown from Te solution above. $b$ ) Photoluminescence spectrum of CdTe grown under Cdoverpressures.

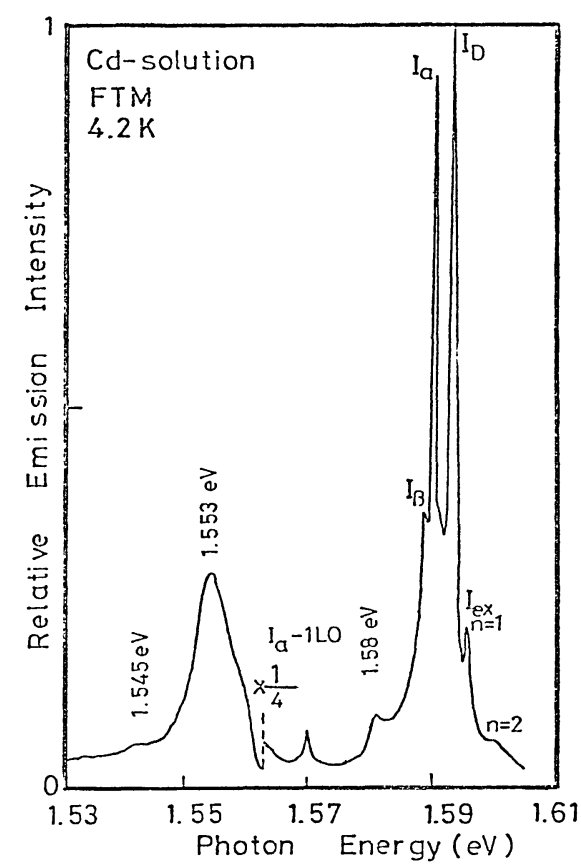

FIG. 8. - Photoluminescence spectrum of CdTe grown from Cd solution.

at $1.553 \mathrm{eV}$ (Fig. 8) assigned to a donor at $\mathrm{E}_{\mathrm{C}}-0.054 \mathrm{eV}$ which could result from a Te vacancy complex [16] althought this is at present pure speculation. 


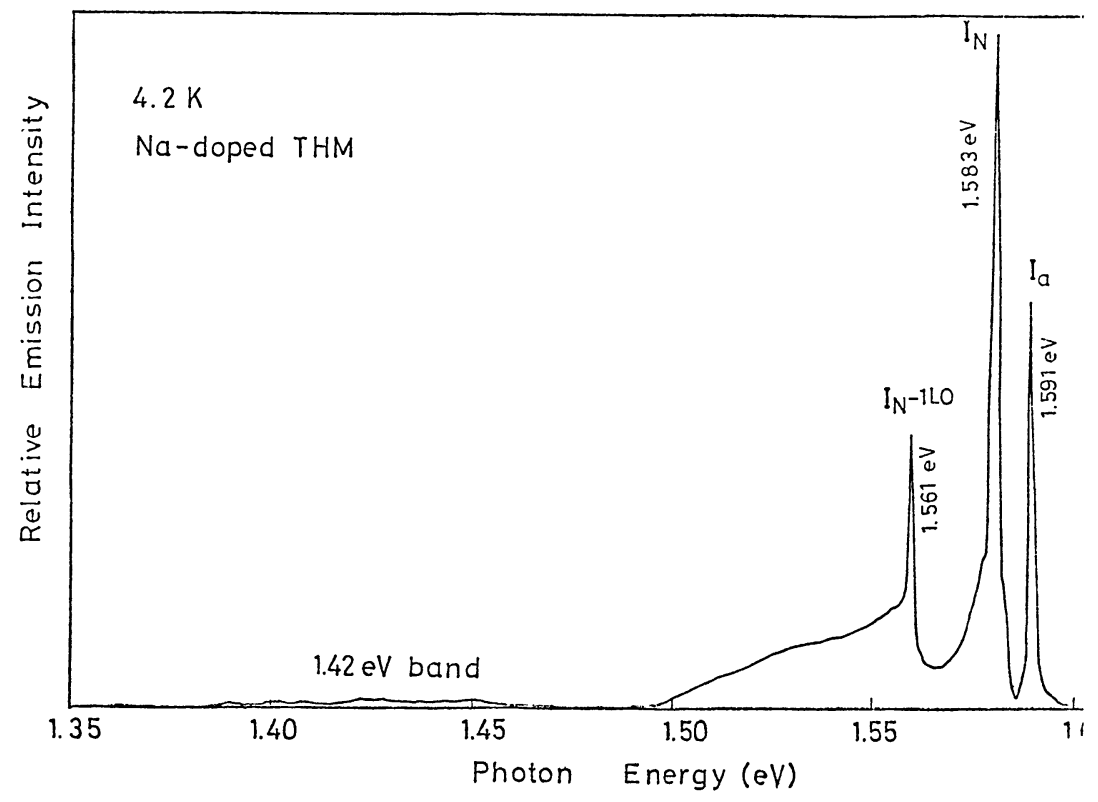

FIG. 9. - Photoluminescence spectrum of $\mathrm{Na}-$ doped CdTe.

However, in accordance with this general model we find that acceptor doping with $\mathrm{Au}$ or $\mathrm{Na}$ has no influence on the intensity of the $1.42 \mathrm{eV}$ emission or indeed may suppress it. Sodium doped crystals specifically show p-type conductivity caused by shallow acceptors at $\mathrm{E}_{\mathrm{v}}+0.026 \mathrm{eV}$. In the photoluminescence spectrum, figure 9, correspondingly, lines at 1.584$1.583 \mathrm{eV}$ are seen which correspond to transitions from the conduction band to acceptors $0.022-0.023 \mathrm{eV}$ above the valence band. In this crystal, furthermore, the $1.42 \mathrm{eV}$ emission band is hardly visible. This suggests to us that $\mathrm{Cd}$ vacancies arealmost absent here, with $\mathrm{Na}$ occupying $\mathrm{Cd}$ site, in particular since no changes were made in the growh experiments. The photoluminescence spectra of $\mathrm{Na}$ doped crystals, therefore, appear to show a way to reduce $\mathrm{Cd}$ vacancy concentration by careful $\mathrm{Na}$ doping.

We have also made a number of detailed measurements of photoluminescence on these crystals on which we have reported previously [17]. We had come to the conclusion there, that in p-type THM grown crystals the most dominant line at $1.59 \mathrm{eV}\left(I_{\alpha}\right)$ is due to annihilation of excitons bound to neutral acceptors which we place at $0.06 \mathrm{eV}$ above the valence band. This idea we feel is further supported by measurements which we have now made in which it can be demonstrated that weakening of the $I_{\alpha}$ line leads to increases in both the intensity of the free exciton line at $1.595 \mathrm{eV}$ and the emission line $I_{0}^{\prime}$ at. $1.545 \mathrm{eV}$ which is the line of the acceptor itself. We have also carried out more detailed experiments using the Zeeman effect to elu- cidate the structure of this acceptor and have come to the conclusion that it is a complex along the [111] direction possessing $\mathrm{C}_{3 \mathrm{v}}$ symmetry [18].

\section{Conclusions. - The Traveling Heater Method} is held to be most useful in growing bulk CdTe single crystals of high purity, since it has been demonstrated here that for crystals grown under optimum thermal and rate conditions, etch pit density, chemical purity, electrical properties and photoluminescence spectra all optimized.

We have also studied the effects of Cd overpressures on the characteristics of the crystals grown. When based on the feed temperature, we can show that a Cd-overpressure of $3 \times 10^{-3} \mathrm{~atm}$. maximizes the room temperature resistivity of undoped p-type crystals grown from $\mathrm{Te}$ solution. It can be as high as $8 \times 10^{6} \Omega . \mathrm{cm}$. However, crystals of the highest resistivity are not necessarily best in terms of electrical transport properties. In fact, these are maximized at over pressures around $10^{-3}$ atom, as will be explored in more detail in our other paper, also presented at this symposium.

However, our attempt to totally suppress $\mathrm{Cd}$ vacancies by Cd-overpressures was not successful, although improvements were achievable. We ascribe this at present to the self compensation tendencies of CdTe.

Acknowledgements. - We are grateful to Dr. Wald and Dr. Bell for critical reading of the manuscript. 


\section{References}

[1] Bell, R. O., Hemmat, N. and Wald, F., Phys. Stat. Sol. (a) 1 (1970) 375.

[2] Triboulet, R. and Marfaing, Y., J. Appl. Phys. 45 (1974) 2759.

[3] TAguchi, T., Shirafuji, J. and InUishi, Y., Japan. J. Appl. Phys. 13 (1974) 1169.

[4] BeLl, R. O. and WALd, F., IEEE Trans. NS-21 (1974) 331.

[5] Siffert, P., Cornet, A., Stuck, R., Triboulet, R. and. MARFAING, Y., IEEE Trans. NS-22 (1975) 211.

[6] Triboulet, R. and Marfaing, Y., J. Electrochem. Soc. 120 (1973) 1260.

[7] Dabrowski, A. J., Chwaszczewska, J., IwanczyK, J., Triboulet, R. and Marfaing, Y., IEEE Trans. NS-23 (1976) 171.

[8] Bell, R. O., Wald, F. and Goldner, R. B., IEEE Trans. NS-22 (1975) 241.

[9] Martini, G. M., Fabre, E., Fogarassy, E., Belin, C. and Ngo-Tich-Phuoc, IEEE Trans. NS-23 (1976) 154.
[10] BARnes, C. E. and ZANIO, K., IEEE Trans. NS-23 (1976) 177.

[11] Malm, H. L. and MARTINI, M., IEEE Trans. NS-21 (1974) 322.

[12] Zanio, K., Krajenbrink, F. and Montano, H., IEEE Trans. NS-21 (1974) 315.

[13] Taguchi, T., Shirafuji, J., Kobayashi, T. and Inuishi, Y., Japan. J. Appl. Phys. Supplement 15 (1976) 267.

[14] Marfaing, Y., Triboulet, R., Furgolle, B., Hoclet, M, and Vandevyver, M., Proc. Intern. Conf. Lattice Defects in Semiconductors, Freiburg, 1974 (The Institute of Physics, London) p. 288.

[15] Whelan, R. C. and Shaw, D., Phys. Stat. Sol. 29 (1968) 145.

[16] KIKUCHI, C., Rad.Eff. 8 (1971) 249.

[17] Taguchi, T., Shirafuji, J. and InUishi, Y., Phys. Stat. Sol. (b) 68 (1975) 146.

[18] Taguchi, T., Shirafuji, J. and Inuishi, Y., Solid State Commun. 19 (1976) 1037. 